\title{
ENERGY EXPENDITURE IN HIIT WHOLE BODY ASSOCIATED WITH ELECTROMYOSTIMULATION
}

\author{
GASTO ENERGÉTICO NO HIIT COM PESO DO CORPO ASSOCIADO À ELETROMIOESTIMULAÇÃO

\section{GASTO ENERGÉTICO EN HIIT CON PESO CORPORAL ASOCIADO A ELECTROESTIMULACIÓN}

ORIGINAL ARTICLE Artículo Original

\begin{abstract}
Alexandre Lopes Evangelista' (iD) (Physical Education Professional) Mario Luis Biffi Pozzi ${ }^{1}$ (DD (Physical Education Professional) Leticia Menezes Santos ${ }^{1}$ iD (Physical Education Professional) Bruna Massaroto Barros² (D) (Physiotherapist)

Cleison Rodrigues de Souza' (ID (Physical Education Professional) Victor Machado Reis ${ }^{3}$ (ID (Profissional de Educação Física)

Danilo Sales Bocalini' iD

(Physical Education Professional)
\end{abstract}

1. Universidade Federal do Espírito Santo, Experimental Physiology and Biochemistry Laboratory of the Center for Physical Education and Sport, Vitória, ES, Brazil. 2. Universidade Nove de Julho, Department of Rehabilitation Sciences, Sao Paulo, SP, Brazil. 3. Research Center for Sport, Health and Human Development, UTAD, Vila real, Portugal.

\section{Correspondence}

Alexandre Lopes Evangelista. Rua Flávio de Melo, 156 apto 12, São Paulo, SP, Brazil. 04117-130. contato@alexandrelevangelista. com.br

\begin{abstract}
Introduction: The use of whole body electromyostimulation (WB-EMS) has been shown to be an efficient method for inducing significant improvements in muscle strength and performance outcomes. Hypothetically, WB-EMS had been considered an enhancer of energy expenditure in the session, but this remains unclear. Objective: In view of the lack of information, this study aims to evaluate the energy expenditure of WB-EMS associated with whole body High-Intensity Interval Training (HIIT). Methods: Fourteen male participants were submitted into two randomized exercise sessions: HIIT ( whole body weight exercises without WB-EMS) and HIIT+WB-EMS ( whole body weight exercises associated with WB-EMS). For both exercise conditions, the subjects performed whole body HIIT according to the following protocol: 3 minutes of warm-up followed by 4 exercises (30 seconds of stimulus) organized in 2 blocks, with 3 sets in each exercise, a rest period of 15 seconds between sets, and 180 seconds between blocks. The following exercises were performed: jumping jacks, squat and thrusts, burpees, and spider plank. Results: Significant differences were found in the absolute $V O_{2}\left(H I I T: 2.18 \pm 0.34, H I I T+W B-E M S: 2.32 \pm 0.36\right.$ L. min $\left.^{-1}\right)$ and relative $V_{2}(H I I T: 26.30 \pm 3.77$, HIIT+WB-EMS:28.02 \pm 3.74 ml.kg.min $\left.{ }^{-1}\right)$, MET (HIIT:7.51 \pm 1.07 , HIIT+WB-EMS:8.00 \pm 1.07 ), lactate concentration (HIIT:11.59 \pm 2.16 , HIIT+WB-

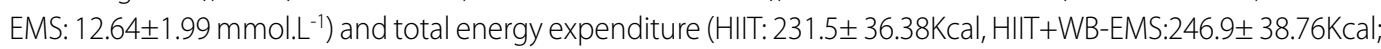
6.14 5.61\%). Conclusion: Our data indicate that the use of WB-EMS associated with HIIT generated a slightly higher metabolic demand than that of the control. However, the absolute differences do not allow us to indicate the superiority of WB-EMS, and future trials should be designed to determine the long-term effects.
\end{abstract}

Keywords: Exercise; Body weight; Energy metabolism; Exercise training.

\section{RESUMO}

Introdução: O uso da eletromioestimulação de corpo inteiro (whole body electromyostimulation - WB-EMS) tem mostrado ser um método eficiente para induzir melhora significativa da força muscular e do desempenho. Hipoteticamente, a prática de WB-EMS foi considerada potencializadora do gasto energético na sessão, mas isso ainda não está claro. Objetivo: Diante da escassez de informações, o objetivo deste estudo foi avaliar o gasto energético da WB-EMS associada ao treinamento intervalado de alta intensidade (HIIT) com o peso corporal. Métodos: Quatorze participantes do sexo masculino foram submetidos a duas sessões de exercícios randomizadas: HIIT (exercícios com peso corporal sem WB-EMS) e HIIT + WB-EMS (exercícios com peso corporal associados a WB-EMS). Para ambas as condições de exercício, os indivíduos realizaram HIIT com peso corporal, de acordo com o seguinte protocolo: $3 \mathrm{mi}$ nutos de aquecimento seguidos de 4 exercícios (30 segundos de estímulo), organizados em 2 blocos com 3 séries em cada exercício, com 15 segundos de descanso passivo entre as séries e 180 segundos entre os blocos, com os seguintes exercícios realizados: jumping jack (polichinelo), squat and thrust, burpee e spider plank. Resultados: Diferenças significativas foram encontradas no consumo de $\mathrm{VO}_{2}$ absoluto (HIIT: 2, 18 $\pm 0,34$, HIIT + WB-EMS: 2,32 $\pm 0,36 ;$ L. $^{-m^{-1}}$ ) e $\mathrm{VO}_{2}$ relativo (HIIT: $26,30 \pm 3,77$, HIIT + WB-EMS: $28,02 \pm 3,74 ; \mathrm{ml}^{\prime} \mathrm{kg} \cdot \mathrm{min}^{-1}$ ), MET (HIIT: 7,51 $\pm 1,07$, HIIT + WB-EMS: 8,00

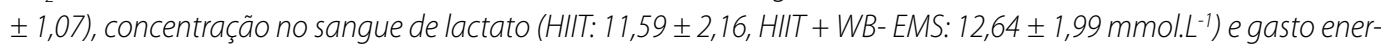

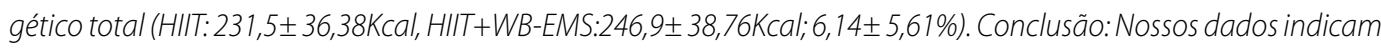
que o uso de WB-EMS associado ao HIIT gerou demanda metabólica ligeiramente superior à do controle. Entretanto, as diferenças absolutas não permitem indicar superioridade do WB-EMS, e estudos futuros devem ser planejados de modo a determinar os efeitos a longo prazo. Nível de evidência II.

Descritores: Exercício físico; Peso corporal; Gasto energético; Treinamento físico.

\section{RESUMEN}

Introducción: Se ha demostrado que el uso de la electroestimulación de cuerpo entero (WB-EMS) es un método eficaz para inducir mejoras significativas en la fuerza musculary los resultados de rendimiento. Hipotéticamente, la práctica de WB-EMS se consideró un potenciador del gasto calórico en la sesión, pero esto aún no está claro. Objetivo: el objetivo del estudio fue evaluar el gasto energético del WB-EMS asociado al HIIT con el peso corporal. Métodos: Se asignaron al azar catorce participantes masculinos a dos sesiones de ejercicio aleatorias: HIIT (ejercicios de peso corporal 
total sin WB-EMS) y HIIT + WB-EMS (ejercicios de peso corporal total asociados con WB-EMS). Para ambas condiciones de ejercicio, los sujetos realizaron HIIT con peso corporal según el siguiente protocolo: 3 minutos de calentamiento seguido de 4 ejercicios (30 segundos de estímulo) organizados en 2 bloques con 3 series en cada ejercicio y 15 segundos entre series y ejercicios y 180 segundos entre bloques de descanso pasivo con los siguientes ejercicios realizados: jump jack, squat and thrust, burpee y spider plank. Resultados: Se encontraron diferencias significativas en el consumo de

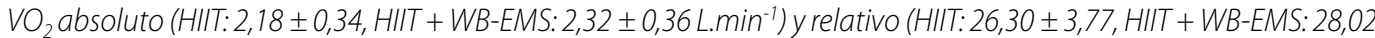
$\pm 3,74 \mathrm{ml} \cdot \mathrm{kg} \cdot \mathrm{min}^{1}$ ), MET (HIIT: 7,51 $\pm 1,07$, HIIT + WB-EMS: 8,00 \pm 1, 07), concentración de lactato (HIIT: 11,59 22,16,

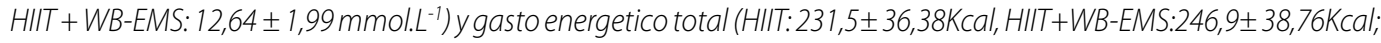
6,14 5,61\%). Conclusión: Nuestros datos indican que el uso de WB-EMS asociado a HIIT generó, en una de manera sutil, una mayor respuesta a la demanda metabólica que la situación de control. Sin embargo, las diferencias absolutas no permiten indicar la superioridad del WB-EMS con estudios futuros y deben planificarse.

Descriptores: Ejercicio físico; Peso corporal; Metabolismo energético; Ejercicio físico.

\section{INTRODUCTION}

High-intensity interval training (HIIT) has presented an increased role in physical activity programs and features among the main fitness worldwide trends. ${ }^{1} \mathrm{HIIT}$ is characteristically composed of high-intensity stimuli interspersed by short periods of active or passive recovery, sequentially repeated in a training session. ${ }^{2}$ The HIIT popularity is due to its better time effciency in terms of outcomes and improvements in physical fitness, ${ }^{3}$ functional capacity ${ }^{4}$ and changes in body composition ${ }^{5}$ in different populations.

HIIT sessions can be performed using standard ergometers. Currently, due to the absence of equipment, there is the possibility to perform HIIT in a wide range of locations being able to maintain the enjoyment of exercise and the intention to continue exercising ${ }^{6,7}$ using whole-body exercises which have been intensively investigated. ${ }^{8-10}$

In the same way, the use of local whole body electromyostimulation (WB-EMS) has shown to be an efficient method to induce significant improvements in muscular strength and performance outcomes on healthy ${ }^{11}$ and disease ${ }^{12}$ subjects with increased on popularity. ${ }^{11,13}$ One reason of its popularity is that the technique allows stimulation of several muscle groups simultaneously; increased activation at different muscle length and contraction modes in a time efficient approaches. ${ }^{14}$

Hypothetically, the WB-EMS practice has been considered such an enhancer of energy expenditure on session, ${ }^{15,16}$ however, to the best of our knowledge there is a gap on literature about energy expenditure and WB-EMS. Thus, considering the lack of information the aim of study was evaluated the energy expenditure of BW+WB-EMS associated with HIIT using whole body.

\section{MATERIALS AND METHODS}

After approval by the research ethics committee of the Federal University of Espírito Santo (CAEE: 37303320.4.0000.5542, № 4.372.208/2020) 14 healthy men $(27.07 \pm 3.54$ years old, $83.14 \pm 7.49 \mathrm{~kg} ; 178 \pm 0.07 \mathrm{~cm}$; $26.38 \pm 2.81 \mathrm{~kg} / \mathrm{m}^{2}$ ) with previous experience in WB-EMS training, but not engaged in any regular exercise program in the past 6 months, were selected. The following parameters were used as exclusion criteria: positive clinical diagnosis of diabetes mellitus, smoking, musculoskeletal complications, and cardiovascular alterations confirmed by medical evaluation.

The subjects were submitted into two randomized exercise sessions, separeted by seven days between them: HIIT (whole body weight exercises without electromyostimulation) and HIIT+WB-EMS (HIIT whole body weight exercises associated to electromyostimulation).

\section{Exercise session regimen}

In both exercise conditions the subjects performed HIIT whole body according to following exercise design: 3 minutes of warm-up (stationary cicling between $60-70 \%$ of maximum heart hate) followed by 4 exercises (30 seconds of stimulus) organized into 2 blocks with 3 sets in each exercise and 15 seconds between sets and exercises and 180 seconds between blocks of passive rest. As showed at Table 1 , the jumping jack, squat and thrust, burpee and spider plank exercises were performed.

To perform the HIIT+WB-EMS condition, the electromyostimulation suit (XBody ${ }^{\oplus}$, Dorsten, Nordrhein-Westfalen, Germany) was adjusted to release a bipolar electrical current with a frequency of $85 \mathrm{~Hz}$, pulse amplitude of $350 \mu s^{17}$ by intermittence for 30 seconds of direct pulse stimulation and 15 seconds of replacement between sets a 180 seconds between blocks as showed at Table 2. Briefly, the WB-EMS suit enables the simultaneous activation of the muscles of legs, arms, gluteals, abdomen, chest, lower back, upper back and shoulders. The HIIT condition was

Table 1. Exercise session regimen.

\begin{tabular}{|c|c|c|c|c|}
\hline \multirow{7}{*}{ Block 1} & Exercise 1 & Exercise 2 & Exercise 3 & Exercise 4 \\
\hline & $\begin{array}{c}30 \text { " of jumping } \\
\text { Jack }\end{array}$ & $\begin{array}{l}30 " \text { of squat } \\
\text { and thrust }\end{array}$ & $30 "$ of burpee & $\begin{array}{c}\text { 30" of spider } \\
\text { plank }\end{array}$ \\
\hline & $15^{\prime \prime}$ rest & $15^{\prime \prime}$ rest & $15^{\prime \prime}$ rest & $15^{\prime \prime}$ rest \\
\hline & $\begin{array}{c}30 \text { " of jumping } \\
\text { Jack }\end{array}$ & $\begin{array}{l}30 " \text { of squat } \\
\text { and thrust }\end{array}$ & $30 "$ of burpee & $\begin{array}{c}\text { 30" of spider } \\
\text { plank }\end{array}$ \\
\hline & $15^{\prime \prime}$ rest & $15^{\prime \prime}$ rest & $15^{\prime \prime}$ rest & $15^{\prime \prime}$ rest \\
\hline & $\begin{array}{c}\text { 30" of jumping } \\
\text { Jack }\end{array}$ & $\begin{array}{l}30 " \text { of squat } \\
\text { and thrust }\end{array}$ & $30 "$ of burpee & $\begin{array}{c}\text { 30" of spider } \\
\text { plank }\end{array}$ \\
\hline & $15^{\prime \prime}$ rest & $15^{\prime \prime}$ rest & $15^{\prime \prime}$ rest & $15^{\prime \prime}$ rest \\
\hline Rest & \multicolumn{4}{|c|}{$3^{\prime}$} \\
\hline \multirow{6}{*}{ Block 2} & $\begin{array}{l}\text { 30" of jumping } \\
\text { Jack }\end{array}$ & $\begin{array}{l}30 " \text { of squat } \\
\text { and thrust }\end{array}$ & $30 "$ of burpee & $\begin{array}{c}\text { 30" of spider } \\
\text { plank }\end{array}$ \\
\hline & $15^{\prime \prime}$ rest & $15^{\prime \prime}$ rest & $15^{\prime \prime}$ rest & $15^{\prime \prime}$ rest \\
\hline & $\begin{array}{c}\text { 30" of jumping } \\
\text { Jack }\end{array}$ & $\begin{array}{l}30 " \text { of squat } \\
\text { and thrust }\end{array}$ & $30 "$ of burpee & $\begin{array}{c}\text { 30" of spider } \\
\text { plank }\end{array}$ \\
\hline & $15^{\prime \prime}$ rest & $15^{\prime \prime}$ rest & $15^{\prime \prime}$ rest & $15^{\prime \prime}$ rest \\
\hline & $\begin{array}{c}\text { 30" of jumping } \\
\text { Jack }\end{array}$ & $\begin{array}{l}30 " \text { of squat } \\
\text { and thrust }\end{array}$ & $30 "$ of burpee & $\begin{array}{c}30 \text { " of spider } \\
\text { plank }\end{array}$ \\
\hline & $15^{\prime \prime}$ rest & $15^{\prime \prime}$ rest & $15^{\prime \prime}$ rest & $15^{\prime \prime}$ rest \\
\hline
\end{tabular}

Table 2. Whole body electromyostimulation protocol.

\begin{tabular}{c|c}
\hline Program variables & Stimulation \\
\hline Stimulation frequency & $85 \mathrm{~Hz}$ \\
\hline Impulse duration & 30 seconds \\
\hline Impulse break & $\begin{array}{r}15 \text { seconds between sets and } \\
180 \text { seconds between blocks }\end{array}$ \\
\hline Pulse breadth & $350 \mu \mathrm{s}$ \\
\hline Impulse type & bipolar \\
\hline Duration & 21 minutes
\end{tabular}


done with the volunteers wearing the electromyostimulation clothing but without receiving any electrical stimulation.

Staff supervised both training sessions, provided verbal encouragement and ensured that the subjects performed the correct number of sets and repetitions with the correct exercise technique.

No restricted dietary control was adopted, but the participants were instructed by an nutritionist not to change their regular dietary intake during the entire study period, besides, were indicated to refrain from any exercise and to avoid taking any supplements, consuming caffeine and energy drinks. The subjects also received general guidance on healthy eating habits at the beginning of the study.

\section{EVALUATED PARAMETERS}

\section{Oxygen uptake and enegy expenditure analyses}

After the warm up, the volume of oxygen expired $\left(\mathrm{VO}_{2}\right)$ during both exercise sessions was measured through a gas analyzer (Fitmate pro; COSMED $^{\circledR}$, Fitmate, Rome, Italy) as described previously. ${ }^{18}$ The gas analyzer was calibrated following the manufacturer's specifications prior to each test. The participants' $\mathrm{VO}_{2}$ was obtained breath-by-breath. The $\mathrm{VO}_{2}$ data was converted into energy units (calorie) using the equivalents of 5.05 calorie (kcal) per liter of oxygen consumed. Additionally, the MET calculation was realized by the following equation: $M E T=V O 2 \div 3,5\left(\mathrm{ml} / \mathrm{kg} / \mathrm{min}^{-1}\right)$.

\section{Blood lactate measurement}

Capillary blood samples were taken from a sterile fingertip using a sterile lancet. The first drop of blood was discarded, and free flow blood was collected in glass capillary tubes. All blood samples $(25 \mathrm{ml})$ for lactate analysis were evaluated using a Accutrend ${ }^{\circledR}$ (Roche - Basel, Switzerland) as previously study. ${ }^{10}$

\section{Heart rate}

The Heart rate (HR) was recorded continuously throughout the training session using Polar HR monitors (Polar Oy, Finland). The HR data were recorded every $5 \mathrm{~s}$. In an attempt to reduce $H R$ recording error during training, all subjects were asked to check their HR monitors before each session and after each block ( 10 min). Following each training session, the HR information was then downloaded to a mainframe computer using Polar Advantage software. The maximal and its percentage of heart rate was estimated using the Tanaka et al equation. ${ }^{19}$

\section{Rate of perceived exertion (RPE)}

The session intensity was measured by the rate of perceived exertion according to previously publication of our group. ${ }^{10}$ Briefly, subjects were told to choose a number from 0 to 10 (maximum value corresponds to the highest physical exertion experienced by the individual, and the minimum value is the rest condition) immediately at the end of each exercise session.

\section{Feeling scale (FS)}

The FS is an 11-point bipolar scale ranging from +5 to -5 , commonly used to measure affective response (pleasure/displeasure) during exercise. This scale presents the following verbal anchors: $-5=$ very bad; $-3=$ bad; -1 = fairly bad; 0 = neutral; +1 fairly good; +3 = good; and $+5=$ very good. Previous studies recommended this scale to measure affective responses during exercise. ${ }^{20}$ The subjects received standard instructions regarding to the use of the FS in the initial screening and before of exercise session. The FS was apllied at the end of each set.

\section{Statistical analysis}

The D'Agostino-Pearson test was applied for Gaussian distribution analysis. A paired Student's t-test was performed to compare differences between conditions. An alpha of 0.05 was used to determine statistical significance. Effect sizes were used in absolute differences between groups using the standardized difference based on Cohen's d units ( $d$ value). The results $d$ were interpreted qualitatively using the following limits: <0.2, trivial; 0.2 - 0.6, small; 0.6 -1.2, moderate; 1.2 - 2.0, large; 2.0 4.0 , very large and; $>4.0$, extremely large. All data values were expressed as the means \pm standard deviations and analyses was performed using GraphPad Prism version 6.0 for Windows (GraphPad Software, La Jolla California, USA) with a significance level of $p<0.05$.

\section{RESULTS}

As showed at Table 3 no differences were found on absolute and relative HR, RPE and feeling scale between HIIT and HIIT+WB-EMS condition. However, significant differences $(p<0.05)$ were found on absolute and relative $\mathrm{VO}_{2}$ uptake, MET and blood lactate concentration.

As showed at Figure 1, significant differences were found on total energy expenditure (HIIT: 231.5 $\pm 36.38 \mathrm{Kcal}, \mathrm{HIIT}+\mathrm{WB}-\mathrm{EMS}: 246.9 \pm$ $38.76 \mathrm{Kcal} ; 6.14 \pm 5.61 \% ; \mathrm{t}=4.20 ; \mathrm{MD}=-15.3 \mathrm{kcal} ; 95 \%$ of $\mathrm{Cl}:-23.25$ to -7.46; $E S=0.41 ; p=0.0010)$, showed at panel $1 \mathrm{~A}$ and time relative en-

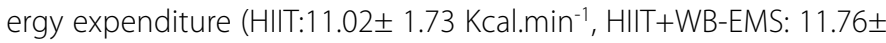
$1.85 \mathrm{Kcal}_{\text {. } \mathrm{min}^{-1}} ; \mathrm{t}=4.25 ; \mathrm{MD}=-0.74 \mathrm{kcal} ; 95 \%$ of $\mathrm{Cl}:-1.11$ to $-0.36 ; \mathrm{ES}=0.41$; $\mathrm{p}=0.0009$ ), showed at panel $1 \mathrm{~B}$.

\section{DISCUSSION}

The main findings of the present study are related to the influence of WB-EMS in promoting an increase in oxygen uptake, lactate concentration and energy expenditure without promoting significant changes, related to control situation, in psychophysiological indicators of monitoring in physical training sessions. To our knowledge, there are few studies that investigated the energy expenditure in exercise sessions that used only body weight ${ }^{21,22}$ as well as the use ofWB-EMS. ${ }^{15}$ In this study, we demonstrated that the use ofWB-EMS intensified the total and relative energy expenditure compared to the control condition, (Figure 1) however, it is worth mentioning that although different, the differences between the sessions corresponded to only $6.14 \pm 5.61 \%$. The total (HIIT: $231.5 \pm 36.38 \mathrm{Kcal}$, HIIT+WB-EMS:246.9 \pm $38.76 \mathrm{Kcal}$ ) and time relative energy expenditure (HIIT:11.02 $\pm 1.73 \mathrm{Kcal}$.

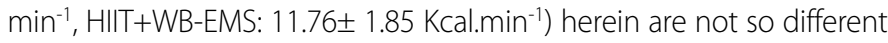
from other modalities that use high intensity training ${ }^{23-26}$ with values comprised between 7.5 to $9.7 \mathrm{Kcal} . \mathrm{min}^{-1}{ }^{1}$.21,22,23-27

To the best of our knowledge there are few studies available on literature ${ }^{15,23}$ evaluating energy expenditure and WB-EMS. BOCCIA et al..23 performed two training sessions of 15 minutes based on isometric intermittent contraction ( 6 seconds of contraction interspersed by 4 seconds of rest) and found energy expenditure of $470 \pm 71 \mathrm{kcal}^{-\mathrm{h}^{-1}}$ and $438 \pm 61$

Table 3. Training parameters comparison of HIIT and HIIT+WB-EMS exercise session.

\begin{tabular}{|c|c|c|c|c|c|c|}
\hline Parameters & HIIT & HIIT+WB-EMS & MD (95\% of Cl) & $t$ & ES & $p$ \\
\hline $\begin{array}{c}\text { Heart rate } \\
(\mathrm{bpm})\end{array}$ & $168.70 \pm 10.34$ & $169.90 \pm 8.80$ & $-1.20(-5.41$ to 3.01$)$ & 0.61 & 0.12 & $=0.5483$ \\
\hline $\begin{array}{c}\text { Heart } \\
\text { rate }(\%)\end{array}$ & $89.14 \pm 5.06$ & $89.79 \pm 5.08$ & $-0.64(-2.93$ to 1.65$)$ & 0.60 & 0.12 & $=0.5553$ \\
\hline $\mathrm{VO}_{2}\left({\mathrm{~L} \cdot \mathrm{min}^{-1}}^{-1}\right.$ & $2.18 \pm 0.34$ & $2.32 \pm 0.36$ & $-0.14(-0.22$ to -0.07$)$ & 4.25 & 0.41 & $=0.0009$ \\
\hline $\begin{array}{l}\mathrm{VO}_{2}(\mathrm{ml} . \\
\left.\mathrm{kg} \cdot \mathrm{min}^{-1}\right)\end{array}$ & $26.30 \pm 3.77$ & $28.02 \pm 3.74$ & $-1.71(-2.58$ to -0.84$)$ & 4.27 & 0.46 & $=0.0009$ \\
\hline MET & $7.51 \pm 1.07$ & $8.00 \pm 1.07$ & $-0.49(-0.74$ to -0.24$)$ & 4.26 & 0.46 & $=0.0009$ \\
\hline $\begin{array}{c}\text { Lactate } \\
\left(\mathrm{mmol} \mathrm{L}^{-1}\right)\end{array}$ & $11.59 \pm 2.16$ & $12.64 \pm 1.99$ & $-1.05(-1.64$ to -0.47$)$ & 3.89 & 0.51 & $=0.0018$ \\
\hline RPE (0-10) & $8.57 \pm 1.60$ & $9.29 \pm 1.38$ & $-0.71(-1.66$ to 0.23$)$ & 1.63 & 0.48 & $=0.1266$ \\
\hline $\begin{array}{c}\text { Feeling } \\
\text { scale }\end{array}$ & $-0.10 \pm 1.87$ & $-0.34 \pm 1.81$ & $0.24(-0.61$ to 1.09$)$ & 0.61 & 0.13 & $=0.5482$ \\
\hline
\end{tabular}

Values expressed as mean \pm standard deviation of HIIT (whole body weight exercises without electromyostimulation) and HIIT+WB-EMS (HIIT whole body weight exercises associated to electromyostimulation). MD = Mean Difference; $\mathrm{Cl}=$ Confidence interval; $\mathrm{ES}=\mathrm{Effect}$ size; $\mathrm{MET}=$ metabolic equivalent; $\mathrm{RPE}=$ rate of perceived exertion 


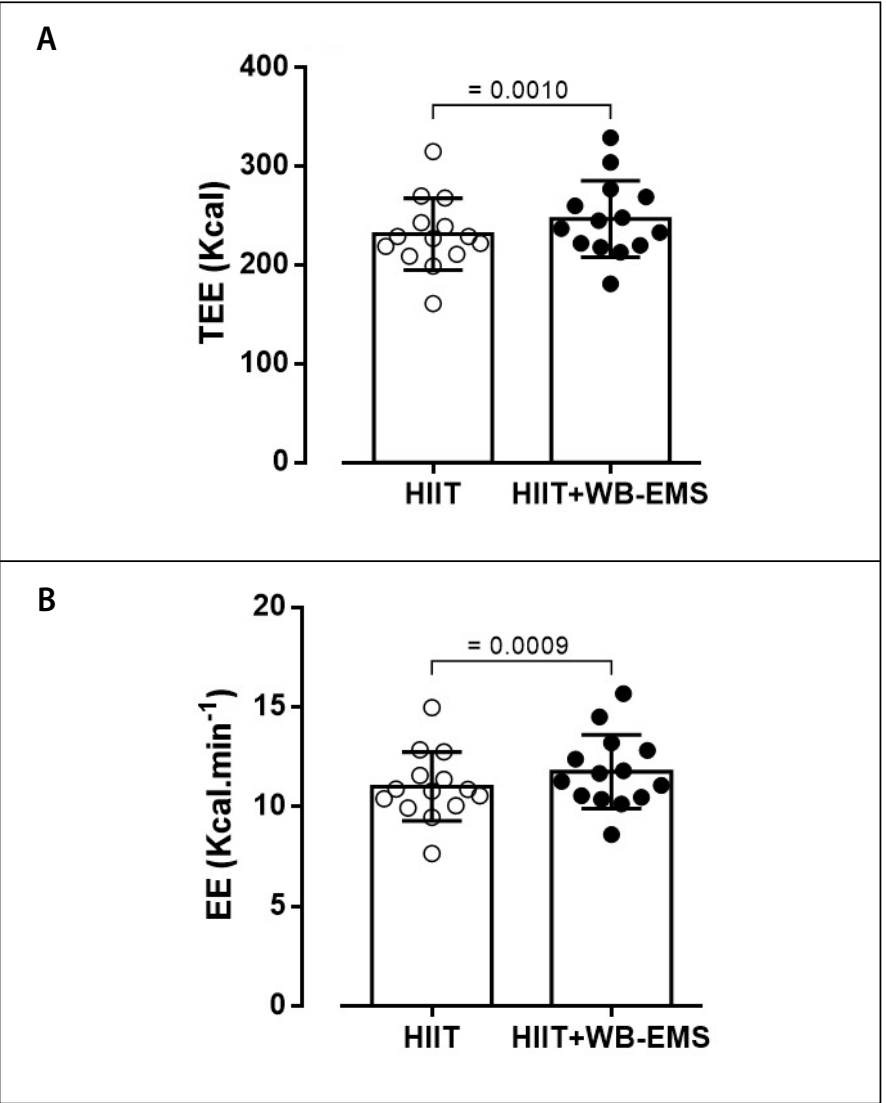

Figure 1. Values expressed as mean \pm standard deviation of HIIT (whole body weight exercises without electromyostimulation) and HIIT+WB-EMS (HIIT whole body weight exercises associated to electromyostimulation). TEE= total energy expenditure; $\mathrm{EE}=$ energy expenditure.

kcal.h ${ }^{-1}$. KEMMLER et al. ${ }^{15}$ demonstrated that, during low-intensity resistance exercise, the use of the WB-EMS provided an increase of approximately $17 \%$ compared to the condition withoutWB-EMS ( $412 \pm 60$ vs. $352 \pm 70 \mathrm{kcal}^{-\mathrm{h}^{-1}}$ ), representing a relative energy expenditure of approximately 6.8 and 5.8 Kcal.min ${ }^{-1}$ and, therefore, lower than that found in the present study. The logical reason that justifies these differences is basically associated with the intensity of effort carried out between the studies, thus the intensity used by KEMMLER et al. ${ }^{15}$ and BOCCIA et al..$^{23}$ may have been considered inferior to that used in the present study. In addition, other indicators should be considered as important influencers in energy expenditure, such as session length, different exercises and gender of the sample. ${ }^{28,29}$

It is known that exercises that present higher oxygen uptake are recognized for promoting greater energy expenditure, in this sense, the use of WB-EMS promoted greater physiological stress, confirmed by the increase in absolute and relative oxygen uptake as well as by the increase in MET and HR. The MET presented in the present study in both conditions (HIIT and HIIT + WB-EMS), although different from each other, were similar to other studies that used high-intensity training using body weight. ${ }^{22}$. It is worth mentioning that studies ${ }^{24,30}$ indicate that exercises with values above 6 METS are considered to be intense. Other intensity indicators popularly used in high-intensity exercise sessions using body weight are $\mathrm{HR}^{10,22}$ and lactate concentration ${ }^{10,31}$. Our data indicated that both sessions corresponded to $89 \%$ of maximum HR and 11 to $12 \mathrm{mmol}^{-\mathrm{L}^{-1}}$ of lactate, values similar to other studies for both HR and lactate concentration that used HIIT with body weight. 10,25,31

The mean values of RPE in the present study are also in agreement with the data available in the literature with HIIT using body weight ${ }^{31,33}$, Additionally, considering the perception of pleasure, there was no difference between both exercise conditions. So, it is possible to consider that the addition of electrical stimulation does not influence this indicator. Thus, our results were similar to other studies that found changes in the perception of pleasure ${ }^{7,20,34}$ with the performance of high-intensity exercises, regardless of the exercise model used.

Some limitations of this study need to be pointed out. This study has a small sample size and was limited to healthy and previous experienced individuals with WB-EMS, in this way any generalizability of the results should be interpreted with caution. An maximal test should also have been applied to confirm fraction of maximal oxygen uptake and \%HR kinetics. Additionally, there is a large variety of HIIT applications on programs and exercise regimes, and the results from this study cannot be applied to other forms of exercise session designs and therefore together these points limit the generalization of the results.

\section{CONCLUSION}

Evidence from our work indicates that the use of WB-EMS associated with HIIT, although subtle, generated greater metabolic demand response than the control session. However, the differences on energy expenditure do not indicate a clear superiority of WB-EMS. Thus, future trials should be designed to determine the long-term effect on health-related outcomes in different populations.

The author Evangelista AL declares a potential conflict of interest because he works as a scientific advisor for XBody ${ }^{\oplus}$. Victor Machado Reis was funded by FCT—Fundação para a Ciência eTecnologia (UID04045/2020).

AUTHORS' CONTRIBUTIONS: Evangelista AL: contributed to the data collection and the intellectual concept of the study, carried out bibliographic research and jointly wrote the manuscript. Pozzi MLB: contributed to the data collection and reviewed the manuscript. Santos LM and Barros BM: contributed to the data collection, carried out bibliographic research and reviewed the manuscript. Souza CR: reviewed the manuscript and contributed to the intellectual concept of the study. Reis VM: reviewed the manuscript and jointly wrote the manuscript. Bocalini DS: evaluated the data from the statistical analysis and jointly wrote the manuscript.

\section{REFERENCES}

1. Thompson W. Worldwide survey of fitness trends for 2020. ACSM's Health \& Fitness Journal. 2019;26(3):10-8.

2. Gibala MJ, Gillen JB, Percival ME. Physiological and Health-Related Adaptations to Low-Volume Interval Training: Influences of Nutrition and Sex. Sports Med. 2014;44(suppl 2):127-37.

3. Naimo MA, de Souza EO, Wilson JM, Carpenter AL, Gilchrist P, Lowery RP, et al. High-intensity interval training has positive effects on performance in ice hockey players. Int J Sports Med. 2015;36(1):61-6.

4. Schaun GZ, Pinto SS, Brasil B, Nunes GN, Alberton CL. Neuromuscular adaptations to six- teen weeks of whole-body high-intensity interval training compared to ergometer-based interval and continuous training. J Sports Sci. 2019;37(14):1561-9.

5. Alves ED, Salermo GP, Panissa VLG, Franchini E, Takito MY. Effects of long or short duration stimulus during high-intensity interval training on physical performance, energy intake, and body composition. J Exerc Rehabil. 2017;13(4):393-9.
6. Heinrich KM, Patel PM, O'Neal JL, Heinrich BS. High-intensity compared to moderate-intensity training for exercise initiation, enjoyment, adherence, and intentions: an intervention study. BMC Public Health. 2014;14:789.

7. Schaun GZ, Alberton CL. Using bodyweight as resistance can be a promising avenue to promote interval training: enjoyment comparisons to treadmill-based protocols. Res Q Exerc Sport. 2020;22:1-9.

8. Evangelista AL, Evangelista RAGT, Machado AF, Miranda JMQ, Scala Teixeira CV, Lopes CR, et al. Effects of high-intensity calisthenic training on mood and affective responses. JEPonline. 2017;20(6):15-23.

9. Evangelista AL, Teixeira CVS, Machado AF, Pereira PE, Rica RL, Bocalini DS. Effects of a short-term of whole-body, high-intensity, intermittent training program on morphofunctional parameters. J Bodyw Mov Ther. 2019;23(3):456-60.

10. Machado AF, Evangelista AL, Miranda JMQ, Teixeira CVL, Leite GS, Baker JS, et al. Description of 
training loads using whole-body exercise during high-intensity interval training. Clinics. 2018;73:e516.

11. Kemmler W, Weissenfels A, Willert S, Shojaa M, von Stengel S, Filipovic A, et al. Efficacy and safety of low frequency whole-body electromyostimulation (WB-EMS) to improve health-related outcomes in non-athletic adults. A systematic review. Front Physiol. 2018;9:573.

12. Wittmann K, Sieber C, Stengel SV, Kohl M, Freiberger E, Jakob F, et al. Impact of whole body electromyostimulation on cardiometabolic risk factors in older women with sarcopenic obesity: the randomized controlled FORMOsA-sarcopenic obesity study. Clin Interv Aging. 2016;11:1697-706.

13. Filipovic A, DeMarees M, Grau M, Hollinger A, Seeger B, Schiffer T, et al. Superimposed Whole-Body Electrostimulation Augments Strength Adaptations and Type II Myofiber Growth in Soccer Players During a Competitive Season. Front Physiol. 2019;10:1187-93.

14. Pano-Rodriguez A, Beltran-Garrido JV, Hernández-González V, Reverter-Masia J. Effects of whole-body ELECTROMYOSTIMULATION on health and performance: a systematic review. BMC Complement Altern Med. 2019;19(1):87.

15. Kemmler W, Von Stengel S, Schwarz J, Mayhew JL. Effect of whole-body electromyostimulation on energy expenditure during exercise. J Strength Cond Res. 2012;26(1):240-5.

16. Teschler M, Wassermann A, Weissenfels A, Fröhlich M, Kohl M, Bebenek M, et al. Short time effect of a single session of intense whole-body electromyostimulation on energy expenditure. A contribution to fat reduction?. Appl Physiol Nutr Metab. 2018;43(5):528-30.

17. Evangelista AL, Teixeira CVS, Barros BM, de Azevedo JB, Paunksnis MRR, Souza CR, et al. Does wholebody electrical muscle stimulation combined with strength training promote morphofunctional alterations? Clinics (Sao Paulo). 2019;74:e1334.

18. Nieman DC, Lasasso H, Austin MD, Pearce S, McInnis T, Unick J.Validation of Cosmed's FitMate in measuring exercise metabolism. Res Sports Med. 2007;15(1):67-75.

19. Tanaka H, Monahan KD, Seals DR. Age - Predicted Maximal Heart Revisited. J Am Coll Cardiol. 2001;37(1):153-6.

20. Frazão DT, de Farias Junior LF, Dantas TC, Krinski K, Elsangedy HM, Prestes J, et al. Feeling of pleasure to high-intensity interval exercise is dependent of the number of work bouts and physical activity status. PLoS One. 2016;11(3):e0152752.

21. Ratamess NA, Rosenberg JG, Klei S, Dougherty BM, Kang J, Smith CR, et al. Comparison of the acute metabolic responses to traditional resistance, body-weight, and battling rope exercises. J Strength Cond Res. 2015;29(1):47-57.
22. Machado AF, Reis VM, Rica RL, Baker JS, Figueira Junior A, Bocalini DS. Energy expenditure and intensity of HIIT bodywork ${ }^{\oplus}$ session. Motriz. 2020;26(4):e10200083.

23. Boccia G, Fornasiero A, Savoldelli A. Oxygen consumption and muscle fatigue induced by wholebody electromyostimulation compared to equal-duration body weight circuit training. Sport Sc Health. 2017;13:121-30

24. Brisebois M. Caloric Expenditure During One Exercise Session Following ACSM and Crossfit ${ }^{\bullet}$ Guidelines [Doctoral dissertation]. Texas Woman's University; 2014

25. Porcari J, Hendrickson K, Foster C. Drop and give me 20. ACE Fitness Matters. 2008;14(4):6-9.

26. Fountaine CJ, Schmidt. BJ. Metabolic cost of rope training. J Strength Cond Res. 2015;29(4):889-93.

27. Willis EA, Szabo-Reed AN, Ptomey LT, Honas JJ, Steger FL, Washburn RA, et al. Energy Expenditure and Intensity of Group-Based High-Intensity Functional Training: A Brief Report. J Phys Act Health. 2019;16(6):470-6.

28. Matsui H, Kitamura K, Miyamura M. Oxygen uptake and blood flow of the lower limb in maximal treadmill and bicycle exercise. Eur J App Physiol. 1978;40(1):57-62.

29. Pinto GS, Abrantes C, Brito JP. Oxygen uptake. heart rate and energy cost during slideboard routines at different cadence. J Sport Med Physical Fitness. 2010;50(2):126-31.

30. Garber CE, Blissmer B, Deschenes MR, Franklin BA, Lamonte MJ, Lee IM, et al. American College of Sports Medicine position stand. Quantity and quality of exercise for developing and maintaining cardiorespiratory, musculoskeletal, and neuromotor fitness in apparently healthy adults: guidance for prescribing exercise. Med Sci Sports Exerc. 2011;43(7):1334-59.

31. Rica R, Miranda JMQ, Machado AF, Evangelista AL, La Scala Teixeira CV, Gama EF, et al. Body-image and size perception after a single session of HIIT body work in healthy adult men. Motricidade. 2018;14(4):66-73.

32. Machado AF, Nunes RAM, Vale RGS, Rica RL, Figueira Juniro AJ, Bocalini DS. High intensity interval training with body weight: the new calisthenics? MTP\&Rehabjourna. 2017;15:(448):1-5

33. Lee HH, Emerson JA, Williams DM. The Exercise-Affect-Adherence Pathway: An Evolutionary Perspective Front Psychol. 2016;7:1285

34. Follador L, Alves RC, Ferreira SS, Buzzachera CF, Andrade VFS, Garcia EDSA, et al. Physiological Perceptual, and Affective Responses to Six High-Intensity Interval Training Protocols. Perceptual and Motor Skills. 2018;125(2):329-50. 